\title{
Habitat quality influences population distribution, individual space use and functional responses in habitat selection by a large herbivore
}

\author{
Kari Bjørneraas • Ivar Herfindal • \\ Erling Johan Solberg • Bernt-Erik Sæther • \\ Bram van Moorter $\cdot$ Christer Moe Rolandsen
}

Received: 9 November 2010/ Accepted: 28 June 2011/Published online: 16 July 2011

(C) The Author(s) 2011. This article is published with open access at Springerlink.com

\begin{abstract}
Identifying factors shaping variation in resource selection is central for our understanding of the behaviour and distribution of animals. We examined summer habitat selection and space use by 108 Global Positioning System (GPS)-collared moose in Norway in relation to sex, reproductive status, habitat quality, and availability. Moose selected habitat types based on a combination of forage quality and availability of suitable habitat types. Selection of protective cover was strongest for reproducing females, likely reflecting the need to protect young. Males showed strong selection for habitat types with high quality forage, possibly due to higher energy requirements. Selection for preferred habitat types providing food and cover was a positive function of their availability within home ranges (i.e. not proportional use) indicating functional response in habitat selection. This relationship was not found for unproductive habitat types. Moreover, home ranges with high cover of unproductive
\end{abstract}

Communicated by Ilpo Kojola.

Electronic supplementary material The online version of this article (doi:10.1007/s00442-011-2072-3) contains supplementary material, which is available to authorised users.

K. Bjørneraas $(\bowtie) \cdot$ I. Herfindal · B.-E. Sæther ·

B. van Moorter . C. M. Rolandsen

Centre for Conservation Biology, Department of Biology,

Norwegian University of Science and Technology,

7491 Trondheim, Norway

e-mail: Kari.Bjorneraas@bio.ntnu.no

E. J. Solberg

Norwegian Institute for Nature Research (NINA),

7485 Trondheim, Norway

C. M. Rolandsen

Naturdata as, 7898 Limingen, Norway habitat types were larger, and smaller home ranges contained higher proportions of the most preferred habitat type. The distribution of moose within the study area was partly related to the distribution of different habitat types. Our study shows how distribution and availability of habitat types providing cover and high-quality food shape ungulate habitat selection and space use.

Keywords Functional response - Resource selection . Reproductive status - Resource utilisation - Sex · Spatial scales · Ungulate

\section{Introduction}

Selection of resources is an important component of a species' ecology (Rosenzweig 1981) and can be regarded as a complex of behaviour and morphology of an animal in a particular environment (Schoener 1971). Animals exploit resources differently to fulfill requirements for growth, survival, and reproduction, and in this way maximise their fitness contribution to future generations (White 1983; McNamara and Houston 1994). The net gain of using a resource may to some extent be influenced by variation in quantity and quality of the resource in relation to costs associated by searching for and exploiting the resource (Charnov 1976; White 1983). A functional response describes how such variability influences resource utilisation (Holling 1959). For herbivores, several regulating mechanisms of this process have been identified, including variation in structure, abundance, and spatial distribution of plants (Spalinger and Hobbs 1992; Hobbs et al. 2003). Accordingly, changes in the composition of available vegetation may affect the animal's foraging behaviour (Hanley 1997). 
Resources come with costs and benefits (Schoener 1971; McNamara and Houston 1994), which may differ among individuals depending on their sex and stage of life, resulting in demographic differences in resource selection (Nikula et al. 2004; Dussault et al. 2005a). In sexually dimorphic ungulates, males may be more selective with respect to good foraging conditions, and utilise larger areas because of their larger body size and higher nutritional needs (Harestad and Bunnell 1979; Herfindal et al. 2009). The mobility of females in the period shortly after parturition can be limited by the presence of young, thus variation in space use or selection of a given resource between males and females or females of different reproductive status may be expected (Main 2008; Van Beest et al. 2011). For instance, females accompanied by young are often the demographic group showing the highest preferences for resources providing cover and protection against predators (White and Berger 2001; Dussault et al. 2005a). Accordingly, differences in resource selection can occur due to individual differences in preferences of habitat types, or because demographic groups segregate and thereby have different availability of resources (Miquelle et al. 1992). The local density of animals may also influence resource selection and the distribution of individuals among different habitat types (Rosenzweig 1991; Maier et al. 2005). According to the ideal free distribution (Fretwell and Lucas 1969), animals should distribute themselves spatially according to resource abundance to maximise their fitness contributions to future generations. As a consequence, differences in local population densities can be expected to match differences in local habitat characteristics (e.g. Maier et al. 2005) but also influence selection for different resources at a finer scale (Rosenzweig 1991).

Resource selection by animals can be identified at multiple scales and habitat selection can be viewed as a part of this hierarchical process of selection (Johnson 1980). The availability of resources within different habitat types may influence the time spent in each habitat type (Brown 1988), and mechanisms influencing resource selection may also apply to habitat selection. For instance, because a habitat does not always contain an adequate mixture of resources, trade-offs between costs and benefits associated with searching, visiting, and utilising the available habitat types will govern the choice of habitat type (Rettie and Messier 2000). Moreover, spatial variation in relative availability of different habitat types may lead to dissimilar habitat selection among similar individuals (Boyce et al. 2003; Godvik et al. 2009; Hansen et al. 2009; Herfindal et al. 2009), termed functional response in habitat selection (Mysterud and Ims 1998). The mechanisms leading to such responses may be related to trade-offs in the allocation of time and energy to different activities, particularly when resources required for different activities are spatially segregated (Mysterud and Ims 1998; Godvik et al. 2009). For instance, use of an open habitat type providing good forage may increase only to a certain threshold despite increasing availability, because the animal prefers to rest in habitat types providing cover.

We studied summer habitat selection and space use by a large ungulate in central Norway during 2006-2008. Using data on 108 Global Positioning System (GPS)-collared moose Alces alces, we first assessed the relationship between habitat selection and the characteristics of different habitat types. We examined: (1) within home range habitat selection; (2) whether females with young (one or two) had stronger selection for protective cover than males and females without young; (3) whether selection for different habitat types was consistent among individuals faced with dissimilar availabilities of the different habitat types; (4) space use by moose at larger scales, expecting availability of habitat types of different qualities to influence home range sizes; and (5) the relationship of local moose density to the spatial distribution of habitat types of different qualities within the study area.

Few large predators are present in Norway (Wabakken et al. 2007; Wartiainen et al. 2009), but moose are heavily harvested by humans. In the study area, moose tend to avoid human activity, a pattern that is clearer for females with young than males (Lykkja et al. 2009). Accordingly, we expected both protective cover and good foraging conditions to be important for the choice of habitat type. However, we expected females with young to show somewhat higher preferences for areas providing protection against predators than males and females without young. Further, we expected individuals inhabiting home ranges that differed in habitat composition to show dissimilar selection for the habitat types (i.e. functional response in habitat selection; Mysterud and Ims 1998). We expected stronger selection when availability of preferred habitat types was low as found in previous studies of ungulates (Godvik et al. 2009; Herfindal et al. 2009). We expected differences in home range habitat composition to cause variation in home range size among individuals of similar individual characteristics, where we predicted home ranges with high proportions of high quality habitats to be smaller. Finally, we expected the local density of moose to be high in areas with high proportion of selected habitat types, and low in areas with high proportion of avoided habitat types.

\section{Materials and methods}

\section{Study area and habitat types}

The study area is located in central Norway (Fig. 1), and ranges from coastal areas to alpine zones by a gentle 


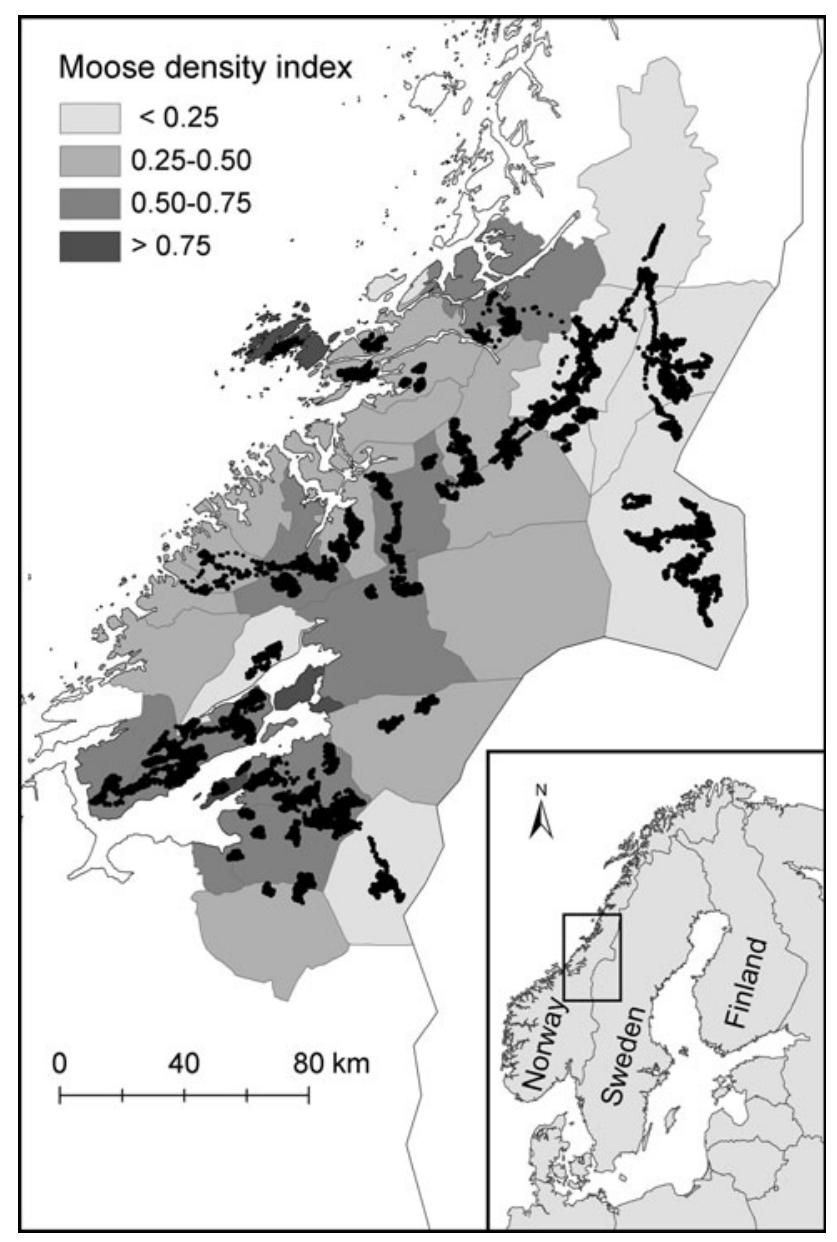

Fig. 1 GPS-locations of 108 moose Alces alces in central Norway during the period June-August 2006-2008. Ten males and 36 females were tracked for 2 years whereas 4 females were tracked for 3 years. The borders show municipalities, for which moose harvested per $\mathrm{km}^{2}$ was estimated as an index of moose density

elevational gradient. Large parts of the area consist of coniferous forest, whereas deciduous and mixed forests cover smaller parts (illustrated in ESM 1). Forest productivity, species composition, and vegetation characteristics vary both among and within forest types. The latter variation is largely due to logging activity, which is most intensive in high-productivity coniferous forest.

To better understand the distribution of plants attractive as moose forage, and thus have a better basis for dividing the forested part of the study area into relevant habitat types, we examined vegetation attributes related to different productivity classes of coniferous, mixed, and deciduous forest. We analysed the density, cover, and age of different plant species in 1,084 permanent study plots $\left(250 \mathrm{~m}^{2}\right)$ surveyed by the Norwegian Forest Inventory in the study area during the period 1995-2004 (Larsson and Hylen 2007). From these data, we estimated the density (i.e. the number of trees with diameter of $\geq 5 \mathrm{~cm}$ at breast height per $1,000 \mathrm{~m}^{2}$ ) of Scots pine Pinus sylvestris, Norwegian spruce Picea abies, birch Betula pubescens and the pooled density of rowan Sorbus aucuparia, aspen Populus tremula, and goat willow Salix caprea. In contrast to pine and spruce, the two latter groups are preferred moose summer forage (Hjeljord et al. 1990; Wam and Hjeljord 2010). Similarly, we estimated the cover (horizontally projected) of deciduous trees in the bush layer $(0.5-2.5 \mathrm{~m}$, i.e. within reach of moose), and the proportion of regenerating forest stands in productive forest. Regenerating forest was defined as forest stands in cutting class 2 $(<25-30$ years old), which typically holds a high density of preferred trees and bushes at accessible heights (Hjeljord et al. 1990). During summer, moose also eat plants from the field layer, particularly bilberry Vaccinium myrtillus and several large forbs and ferns (Hjeljord et al. 1990). Norwegian Forest Inventory sample plots provide information on the cover of bilberry (horizontally projected cover of bilberry in four $0.25-\mathrm{m}^{2}$ areas within each study plot), but not forbs and ferns. To get an index of the distribution of forbs and ferns, we therefore calculated the proportion of sample plots with the two most important vegetation types with high cover of these plants (i.e., tall fern and tall herb woodland). Lastly, we examined distance to roads and average altitudinal location for the different forest types.

On average, coniferous forest had high density of spruce (high-productivity) or pine (low-productivity), but relatively low densities of rowan-aspen-willow, birch and deciduous bushes (Fig. 2a-e). In contrast, coniferous forest had the highest proportion of young forest stands, particularly at high-productivity land, and intermediate cover of bilberry (Fig. 2f, g). The mixed and deciduous forests had higher densities of rowan-aspen-willow and birch, and also high proportions of attractive moose forage in the field-layer vegetation dominated by tall herb and tall fern woodland (Fig. 2c, d, h). Thus, feeding conditions from the perspective of a moose seemed to be best in deciduous forest but were also good in high-productivity mixed and coniferous forest. However, as high-productivity forests were located at lower altitudes and closer to roads (Fig. 2i, j), human disturbance may interact to some extent with the expected preferences for these habitat types (Nikula et al. 2004; Lykkja et al. 2009).

Based on the findings above (Fig. 2), we categorised the forest in the study area into six forest habitat types (three species categories each divided into two productivity classes; Table 1). In addition, we identified three nonforested habitat types: agricultural land, bog, and barren land (Table 1). Bog and barren land are not, or very sparsely, covered with trees, and assumed to provide little forage for moose. For agricultural land, we had no specific information about the crop produced on each habitat patch. 
Fig. 2 Characteristics and distribution of vegetation and physical attributes in the forested habitats. Data are based on 1,084 permanent study plots $\left(250 \mathrm{~m}^{2}\right)$ monitored by the Norwegian Forest Inventory in the study area during 1995-2004. Low and high indicate the productivity of the forest. Parameter values $(+1 \mathrm{SE})$ are from generalised linear models. $R A G$ denotes the pooled density of rowan, aspen and goat willow. Trees per hectare indicate the density of trees. The cover of bilberry and deciduous trees and bushes within the height interval $0.5-2.5 \mathrm{~m}$ is horizontally projected. Young forest shows the proportion of plots with regenerating forest, i.e. cutting class 2 . Forbs and fern indicate the proportion of study plots with vegetation types with high density of large forbs and ferns. Average distance to nearest high quality road and average altitude is given. Asterisk means not relevant
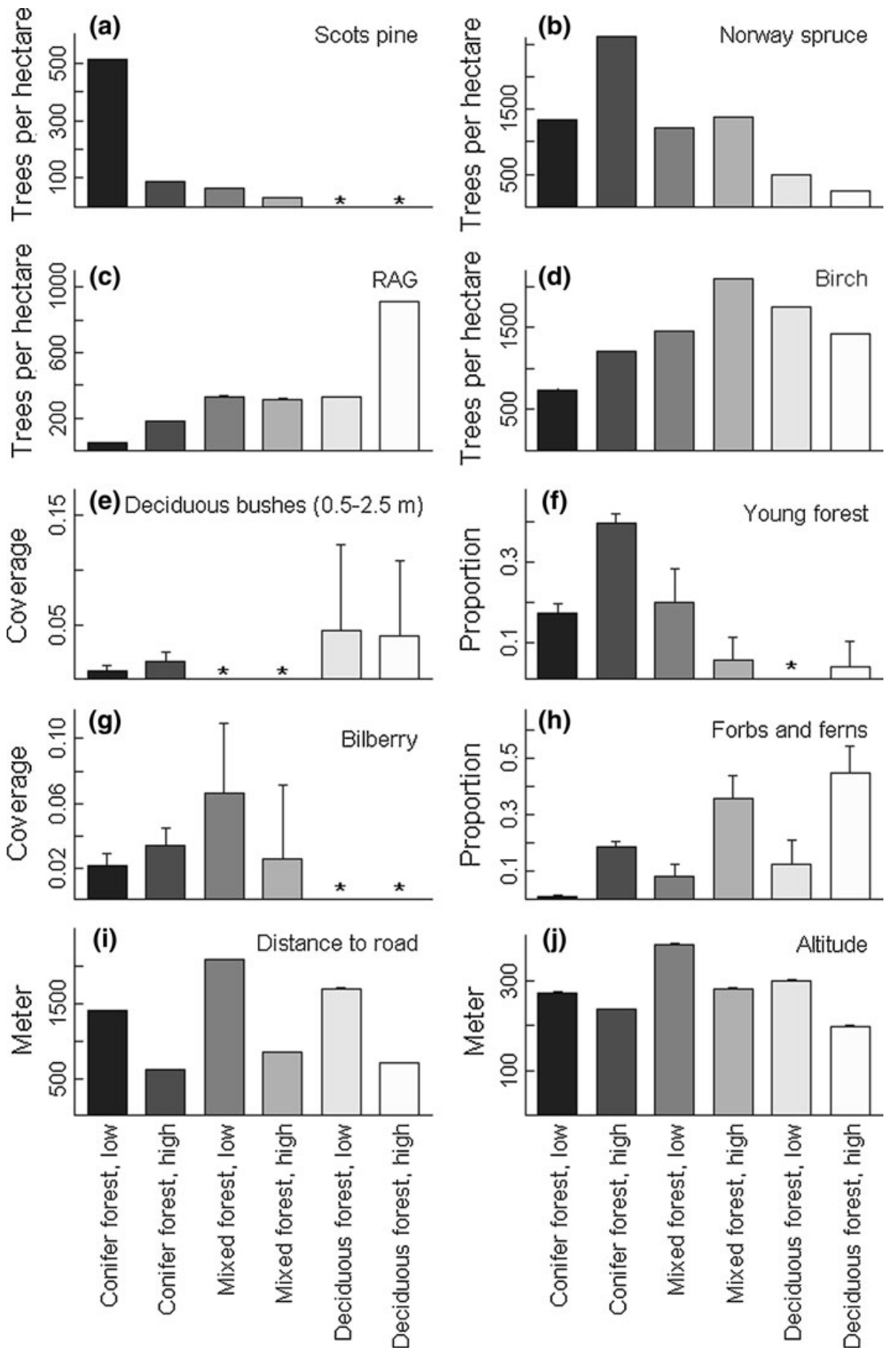

However, most agricultural land in the study area is used for grass (hay or silage) or grain production, both of which are frequently utilised as food by moose during the growing season. We used digital land cover maps $(1: 5,000)$ provided by the Norwegian Forest and Landscape Institute to identify the location of the habitat types within the study area (Bjørdal and Bjørkelo 2006). The map was converted to a $25 \mathrm{~m} \times 25 \mathrm{~m}$ grid system, where each pixel was characterised by the dominant habitat type present.
Moose data

We used location data for 108 adult moose (25 males and 83 females) acquired from GPS-collars with very high frequency transmitters manufactured by Vectronic Aerospace $(n=106)$ and Televilt $(n=2)$. The number of moose captured in each moose management area within the study area was decided based on expected overall density and local knowledge about moose density during winter. 
Table 1 Description of habitat types and productivity classes

\begin{tabular}{|c|c|c|c|c|c|}
\hline $\begin{array}{l}\text { Habitat type/ } \\
\text { productivity } \\
\text { class }\end{array}$ & Description & $\begin{array}{l}\text { Productivity } \\
\text { class }\end{array}$ & $\begin{array}{l}\text { Males } \\
(n=35)\end{array}$ & $\begin{array}{l}\text { Females } \\
\text { with young } \\
(n=113)\end{array}$ & $\begin{array}{l}\text { Females } \\
\text { without } \\
\text { young } \\
(n=14)\end{array}$ \\
\hline \multirow{2}{*}{$\begin{array}{l}\text { Deciduous } \\
\text { forest }\end{array}$} & \multirow{2}{*}{$\begin{array}{l}\text { Areas with }>5 \text { trees (which can become }>5 \mathrm{~m} \mathrm{tall} \text { ) per } 1,000 \mathrm{~m}^{2} \text {, } \\
\text { where less than } 20 \% \text { of the wooded land is covered by coniferous } \\
\text { forest }\end{array}$} & Low & 31 & 72 & 12 \\
\hline & & High & 30 & 64 & 13 \\
\hline \multirow[t]{2}{*}{ Mixed forest } & \multirow{2}{*}{$\begin{array}{l}\text { Areas with }>5 \text { trees (which can become }>5 \mathrm{~m}^{\text {tall }}{ }^{\mathrm{a}} \text { ) per } 1,000 \mathrm{~m}^{2} \text {, } \\
\text { where } 20-50 \% \text { of the wooded land is covered by coniferous forest }\end{array}$} & Low & 32 & 76 & 11 \\
\hline & & High & 35 & 86 & 13 \\
\hline \multirow{2}{*}{$\begin{array}{l}\text { Coniferous } \\
\text { forest }\end{array}$} & \multirow{2}{*}{$\begin{array}{l}\text { Areas with }>5 \text { trees (which can become }>5 \mathrm{~m} \text { tall }{ }^{\mathrm{a}} \text { ) per } 1,000 \mathrm{~m}^{2} \text {, } \\
\text { where more than } 50 \% \text { of the wooded land is covered by coniferous } \\
\text { forest }\end{array}$} & Low & 35 & 112 & 14 \\
\hline & & High & 35 & 113 & 14 \\
\hline $\begin{array}{l}\text { Agricultural } \\
\text { land }\end{array}$ & $\begin{array}{l}\text { Areas used for cultivation, arranged for mechanical harvesting and } \\
\text { areas with }>50 \% \text { cover of grass without possibility for mechanical } \\
\text { harvesting }\end{array}$ & & 32 & 71 & 11 \\
\hline Bog & Areas with $>29 \mathrm{~cm}$ peat and bog characterised surface & & 35 & 112 & 14 \\
\hline Barren land & $\begin{array}{l}\text { Areas with covered by rock and/or with low soil depth, and areas not } \\
\text { categorised by the mapping institute, mainly consisting of land } \\
\text { above the tree line }\end{array}$ & & 35 & 112 & 14 \\
\hline $\begin{array}{l}\text { Low- } \\
\text { productivity }\end{array}$ & Timber productivity capacity $<0.3 \mathrm{~m}^{3}$ per decare and year & & & & \\
\hline $\begin{array}{l}\text { High- } \\
\text { productivity }\end{array}$ & Timber productivity capacity $>0.3 \mathrm{~m}^{3}$ per decare and year & & & & \\
\hline
\end{tabular}

The number of home ranges including the different habitat types is given for three groups of moose: males, females with young and females without young. Data are from moose from central Norway during the period June to August in three consecutive years

${ }^{a}$ In mountain forest or coastal forest where trees are lower due to different growth conditions, the high requirement is $3 \mathrm{~m}$ for the dominating species

The proportion of females compared with males in the sample is probably close to the sexual distribution of adults in the population (Rolandsen et al. 2010; National Cervid Register 2011). We used data from 2006-2008. Ten males and 36 females were tracked for 2 years, and 4 females were tracked for all 3 years. To monitor reproductive status, we tracked and observed all females once or several times a year using very high frequency signals. We categorised females into two groups: females with one or more calves and females without young.

For the analysis, we used location data for every second hour. The data were screened for errors and approximately $0.01 \%$ of the locations were removed (Bjørneraas et al. 2010). All moose included in the analyses had more than 150 positions from each month of the study period (i.e. a minimum of five locations every day), which gave an average of 1,083 locations for each moose per year (range $=759-1,105)$. As $97.4 \%$ of the locations were three-dimensional and the fix success rate was $98.1 \%$, the GPS-locations were not differentially corrected. We therefore assume that the observations reflect the true spatial distribution of the marked individuals.

The study period, 1 June-31 August, includes large parts of the vegetation growing season in the area (Karlsen et al. 2006), but ends before the hunting (start at 25 September) and rutting season (peak around 1 October; Garel et al. 2009). Calving occurs in late May and early June (Rolandsen et al. 2010).

Moose populations in Norway are regulated by harvesting, whereas predation only has a minor effect on the population growth rates $(<30$ bears Ursus arctos and $<5$ wolves Canis lupus were present in the study area; Wartiainen et al. 2009; Wabakken et al. 2007). Therefore, there is a relatively close relationship between fluctuations in population density and number of moose harvested in Norwegian populations (Solberg et al. 1999). This relationship was utilised to estimate an index of local density as the number of moose harvested per $\mathrm{km}^{2}$ of moose inhabitable habitat (i.e. below the forest line, excluding developed areas and open water) (Solberg et al. 1999). We estimated the indices of local population densities for each municipality (Fig. 1), which is the smallest available spatial resolution for harvest data.

\section{Assessment of habitat use}

To relate space use by moose to different habitat types, we estimated utilisation distributions (UDs). UDs consider use as continuous rather than a discrete occurrence (i.e. used vs. not used) (Marzluff et al. 2004). The UDs were 
calculated annually for each moose by the Brownian bridge movement model (BB) (Horne et al. 2007) utilising a $25 \mathrm{~m} \times 25 \mathrm{~m}$ grid system (i.e, to fit the GPS precision and the resolution of the habitat map), using the adehabitat package (Calenge 2006) in R. A BB is a Brownian motion conditioned on a starting and an ending location, and is a continuous time stochastic model of movement estimating the probability that the animal occurred in an area over a specific period of time (Horne et al. 2007). We chose to use BB because this model incorporates the animal's movement path as well as the time between locations in the model (Horne et al. 2007). Since the BB assumes that locations are dependent, the model can be useful because it allows for use of large amounts of data that may cover different modes of animal behaviour and may give more precise representations of home ranges (Horne et al. 2007). Moreover, the selection of the smoothing factors in a BB is rather objective because the smoothing is based on a measure of mean GPS location error $(\delta)$ and the Brownian motion variance $\left(\sigma_{\mathrm{m}}^{2}\right)$ (Horne et al. 2007). The home range boundaries were set to $90 \%$ of the space use estimated by the $\mathrm{BB}$, trying to avoid inclusion of non-used areas and following recommendations for other home range estimators (Börger et al. 2006). A previous study comparing home range models suggests that $\mathrm{BB}$ is suitable only when home range size is relatively large (Huck et al. 2008), which is commonly found for moose (e.g. Herfindal et al. 2009).

For each pixel within a home range, a UD value was calculated. This value is the probability that the individual was located within the given pixel during a given period (June-August) relative to other pixels within the home range (Marzluff et al. 2004). The sum of all UD values associated with a particular habitat is the total probability of occurrence in that habitat (Marzluff et al. 2004). Further, an index called concentration of use is obtained by dividing this sum by the availability of the focal habitat (Neatherlin and Marzluff 2004). Hence, concentration of use is a measure of habitat use in relation to habitat availability, analogous to other selection coefficients, but is an improvement over traditional selection coefficients (for discussion, see Neatherlin and Marzluff 2004). For comparison of habitat selection among individuals, relative concentration of use was estimated by scaling concentration of use to a value between 0 and 1 within each individual home range. We defined individual availability of a habitat type as the proportion of that habitat inside the home range. To give a description of habitat distribution in central Norway, the cover of the different habitat types in the overall study area was calculated. Spatial autocorrelation in usage of habitat types is likely to be a result of spatial autocorrelation in the habitat values, and is expected to be captured by the statistical model applied (Aarts et al. 2008).
Statistical analyses

The first analysis tested whether moose preferred some habitat types to others by comparing concentration of use of different habitat types between home ranges. Next, we tested whether habitat selection differed among males and females with and without young (demographic class), where the habitat specific concentration of use was the response variable. Similarly, we compared home range composition among these demographic classes, using proportion of different habitat types within a home range as response variable. Home range size was ln-transformed, whereas the habitat-specific concentration of use and proportion available within a home range were logit-transformed to reduce heteroscedasticity. We used linear mixed effect models (Pinheiro and Bates 2000) from the $\mathrm{R}$ package lme4 (Bates and Maechler 2008) to examine these relationships. We added individual moose as a random factor to account for within-individual dependency among the observations and because we were interested in the population and not the individual moose (Pinheiro and Bates 2000). To evaluate uncertainty of parameter estimates from the linear mixed effect models, we ran 10,000 Markov Chain Monte Carlo resamplings from the posterior distribution of the parameter estimates from the fitted models, using the function mcmcsamp in lme4. Parameter estimates for which the $95 \%$ confidence interval $(95 \% \mathrm{CI}$, defined by the 2.5 and $97.5 \%$ quantiles from the resampled distributions) did not overlap with zero were considered significant. In biological terms, this means that, when comparing the selection of habitat types and the $95 \%$ $\mathrm{CI}<0$, the focal habitat type is avoided relative to the other. A $95 \%$ CI $>0$ indicates that the habitat type is selected, whereas a CI overlapping zero indicates no significant avoidance or selection of the habitat type.

We also tested if relative availability of the different habitat types within the respective home ranges affected home range size of males, and females of different reproductive status. To examine this, we used generalised additive mixed models (GAMMs) because they allow for both linear and non-linear response shapes (Wood 2006), and are well suited for describing non-linear relationships in habitat selection studies (Aarts et al. 2008). A non-linear response was indicated when the estimated degrees of freedom $(e d f)$ of the smooth function $>1$, whereas $e d f=1$ indicated a linear response. Home range size was the response variable and the proportion of different habitat types within the home range was the explanatory variable. We added individual moose as a random factor.

Next, we examined functional response as the relationship between concentration of use and relative habitat availability for all nine habitat types, using GAMMs (Wood 2006). Because concentration of use is defined as 
the probability of occurrence of an animal in a particular habitat type divided by the habitat availability, a slope of zero corresponds to an animal showing a constant habitat preference regardless of changes in habitat availability, (i.e. proportional use). Therefore, we defined functional response as a slope that deviated from zero, because that means that selection for a habitat type changed with varying availability. Similar to the other models, we added individual moose as a random factor.

Lastly, we examined any relationship between the moose density index and the proportion of the different habitat types (Table 1) in the municipalities using linear models. We excluded mountainous areas (not included in the land cover map) from this analysis, as this would otherwise provide a wrong estimate of the availability of habitat types commonly used by moose. As the measure of density available for the study area is too coarse to reflect the intra-specific competition within different habitat types, relationships between the moose density index and habitat selection or home range size were not examined.

To evaluate the robustness of the results obtained from the analyses based on the $\mathrm{BB}$, we examined habitat selection and home ranges by applying different methods to the data (see ESM 2). We performed all analyses in R for Windows version 2.11.1 (R Development Core Team 2010).

\section{Results}

\section{Habitat selection}

For all moose pooled, concentration of use differed among habitat types $\left(F_{8,1225}=19.46, P<0.0001\right.$; Fig. 3$)$. Highproductivity coniferous forest was abundant (Fig. 4) and provided relatively good forage in addition to cover (Fig. 2). Moose used this habitat type most frequently relative to its availability within the home ranges (Fig. 3).

Reproducing females selected high-productivity coniferous forest over the eight other habitat types $(95 \% \mathrm{CI}$ of the difference between high-productive coniferous forest and the eight other habitat types were $>0$ ). They also selected low-productivity coniferous forest over all habitat types except high-productivity coniferous forest (all 95\% $\mathrm{CI}$ of the difference between low-productive coniferous forest and the seven other habitat types were $>0$ ). For females without young, concentration of use of high-productivity coniferous forest did not differ from either lowproductivity coniferous forest $(95 \% \mathrm{CI}:-0.008,0.083)$, agricultural land (95\% CI: $-0.037,0.067)$ nor bog $(95 \% \mathrm{CI}$ : $-0.001,0.084)$. Males showed pronounced selection for habitat types providing good forage conditions; it was not possible to separate between their selective use of high-

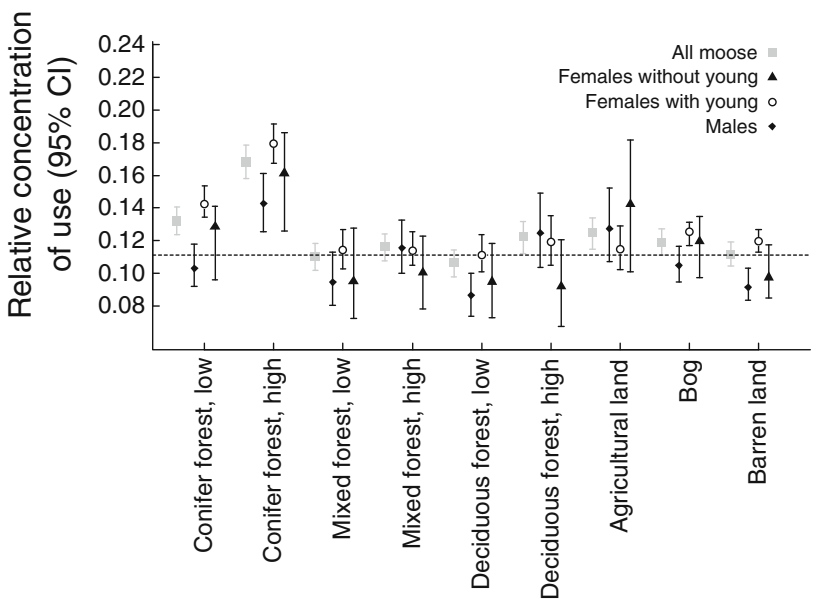

Fig. 3 Within home range habitat selection, indicated by concentration of use (i.e., the volume of the utilisation distribution associated with the habitat divided by the within home range habitat availability) for moose with different individual characteristics. Grey squares show relative concentration of use for all moose pooled. Parameter values are from linear mixed effect models with individual moose included as random factor. Bars represent $95 \%$ confidence intervals of the estimates. The dashed line indicates mean probability of occurrence expected for random use of habitat types within home ranges given that all habitat types are included in each home range. Low and high indicate the productivity of the forest. For description of habitat types and number of moose in each habitat, see Table 1

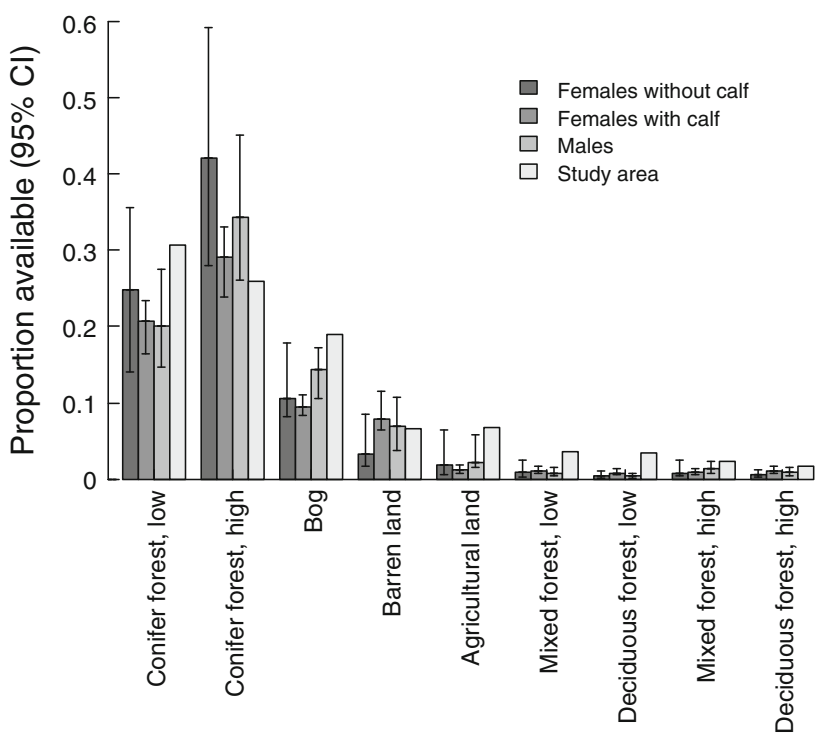

Fig. 4 Average proportions of habitat types within home ranges for moose with different individual characteristics in central Norway during summer in three consecutive years. The proportions were estimated using linear mixed effect models with individual moose included as a random factor in order to test if proportions differed among the three classes of moose. Bars represent $95 \%$ confidence intervals of the estimates. Low and high indicate the productivity of the forest. For description of habitat types and number of moose in each habitat, see Table 1. Proportions of the different habitat types within the overall study area are shown for comparison 
productivity coniferous forest and high-productivity deciduous forest $(95 \% \mathrm{CI}:-0.006,0.041)$ or agricultural land (95\% CI: $-0.020,0.037)$. The selection of high-productivity deciduous and mixed forest over the low-productivity alternatives strengthened the evidence of male preference for food-rich habitat types $(95 \%$ CI: 0.019 , 0.059 and $95 \%$ CI: 0.001, 0.039, for deciduous and mixed forest, respectively). We did not find females with and without young to select high-productivity deciduous and mixed forest over the low-productivity alternatives (all 95\% CI of the difference between high-productive and low-productive mixed and deciduous forest included zero).

Contrary to our expectation, concentration of use of barren land for males did not differ significantly from the use of low-productivity deciduous forest (95\% CI: -0.001 , $0.023)$, low-productivity mixed forest $(95 \% \mathrm{CI}:-0.020$, $0.014)$, low-productivity coniferous forest (95\% CI: -0.029 , $0.005)$ or bog (95\% CI: $-0.030,0.005)$. For females, barren land was selected significantly less than coniferous forest (females with young: $95 \% \mathrm{CI}$ : $-0.037,-0.011$ and $95 \% \mathrm{CI}$ : $-0.074,-0.044$ for low- and high-productivity, respectively. Females without young: 95\% CI: $-0.098,-0.011$ for highproductivity only), but not significantly less than the other habitat types (all 95\% CI of the difference between barren land and the remaining habitat types included zero).

\section{Home range size and composition}

Male home ranges averaged $11.0 \mathrm{~km}^{2}(\mathrm{SD}=8.7)$, whereas females with and without young used areas of $5.0 \mathrm{~km}^{2}$ $(\mathrm{SD}=4.7)$ and $7.4 \mathrm{~km}^{2}(\mathrm{SD}=4.1)$, respectively. Coniferous forest comprised the largest part of the total area within home ranges, followed by bog (Fig. 4). Compared with the overall study area, moose home ranges tended to include a higher proportion of the most selected habitat; high-productivity coniferous forest (Fig. 4). The composition of home ranges differed slightly between males and females with young where the average male home range included a smaller proportion of low-productivity deciduous forest (95\% CI: $-0.011,-0.001)$ and a larger proportion of agricultural land (95\% CI: $0.002,0.046)$ and bog $(95 \%$ CI: $0.007,0.079)$. Home ranges of females without young did not differ in composition from either males or females with young (all 95\% CIs included zero). Water bodies constituted an average proportion of $0.013(\mathrm{SD}=0.017)$ of the home range size.

The availability of several habitat types influenced home range size (Fig. 5). Home range size decreased linearly $(e d f=1)$ with increasing proportion of agricultural land (females without young: $\beta=-0.30, P=0.031$; females with young: $\beta=-0.37, P<0.001$; and males: $\beta=-0.35$, $P=0.013$; home range size and proportion are on log and logit scales, respectively). Male home range size decreased with increasing proportion of high-productivity coniferous forest $(\beta=-0.38, P=0.005)$, which was also the case for females accompanied by young (Fig. 5). The latter relationship was not linear $(e d f=2.34, P<0.001)$, but a decline was clearly present when the home ranges reached a threshold of high-productivity coniferous forest (approximately 0.10). In contrast, home range size increased $(e d f=1)$ with increasing proportion of bog for males ( $\beta=0.53, P=0.013)$ and females with young $(\beta=0.22$, $P=0.003$; Fig. 5). We found similar relationships for barren land $(\beta=0.49, P<0.001$ and $\beta=0.20, P<0.001$ for males and females with young, respectively; Fig. 5) and low-productivity coniferous forest (males only: $\beta=0.26$,
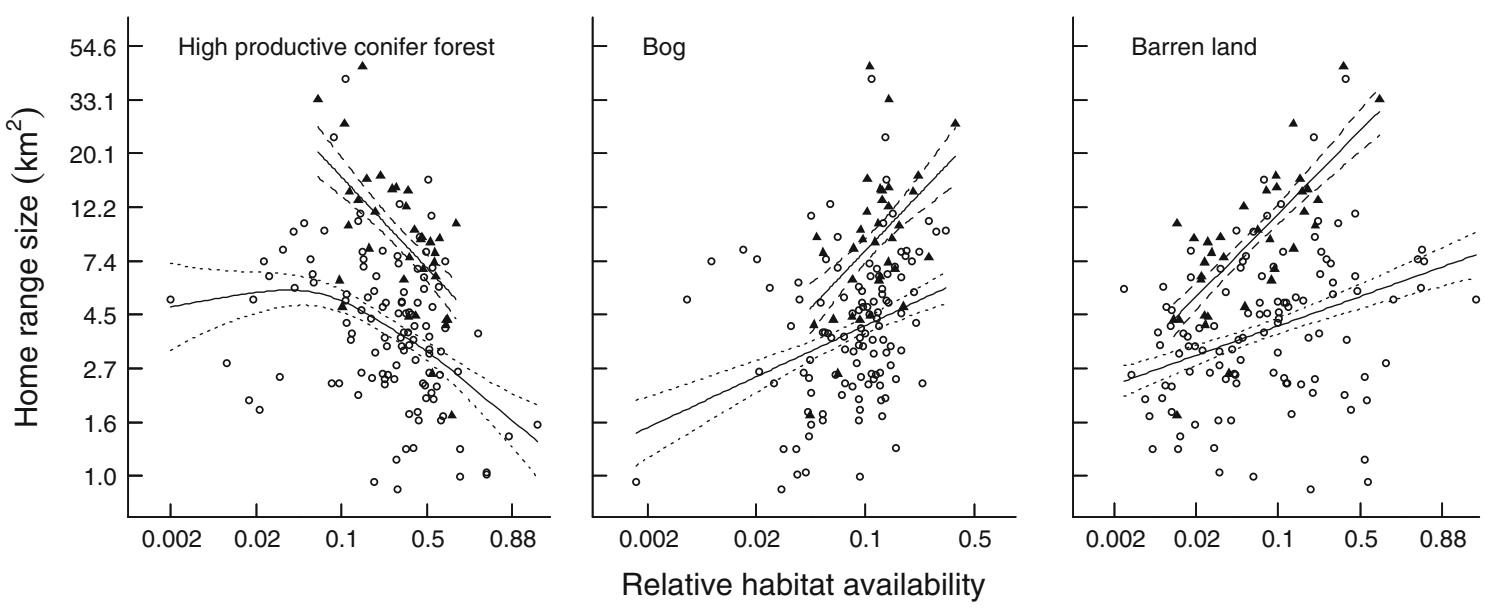

Fig. 5 The relationship between moose home range size $\left(\mathrm{km}^{2}\right)$ and relative proportion habitat available within the home range. Triangles show the relationship for males, and open circles for females with young. The relationships were modelled using generalised additive mixed models, including individual moose as a random factor.
Dashed and dotted lines indicate 1SE for males and females with young, respectively. Notice the $\log$ and the logit scale on the $y$ - and $x$-axes, respectively. See Table 1 for habitat description and for number of moose per habitat. See "Results" for estimated degrees of freedom $(e d f)$ of the smooth functions 
Fig. 6 The relationship between proportion available of a given habitat within the moose summer home ranges and the relative concentration of use of the habitat. Concentration of use is the volume of the utilisation distribution associated with the habitat divided by the within home range availability of the habitat, indicating habitat selection. Thus, a slope deviating from zero indicates that selection changes disproportionally with availability. The relationships were modelled using generalised additive mixed models, including individual moose as a random factor. Dashed lines indicate 1SE. Low and high indicate the productivity of the forest. Notice the logit scale on the $x$-axes. See Table 1 and "Materials and methods" for further descriptions and "Results" for estimated degrees of freedom $(e d f)$ of the smooth functions

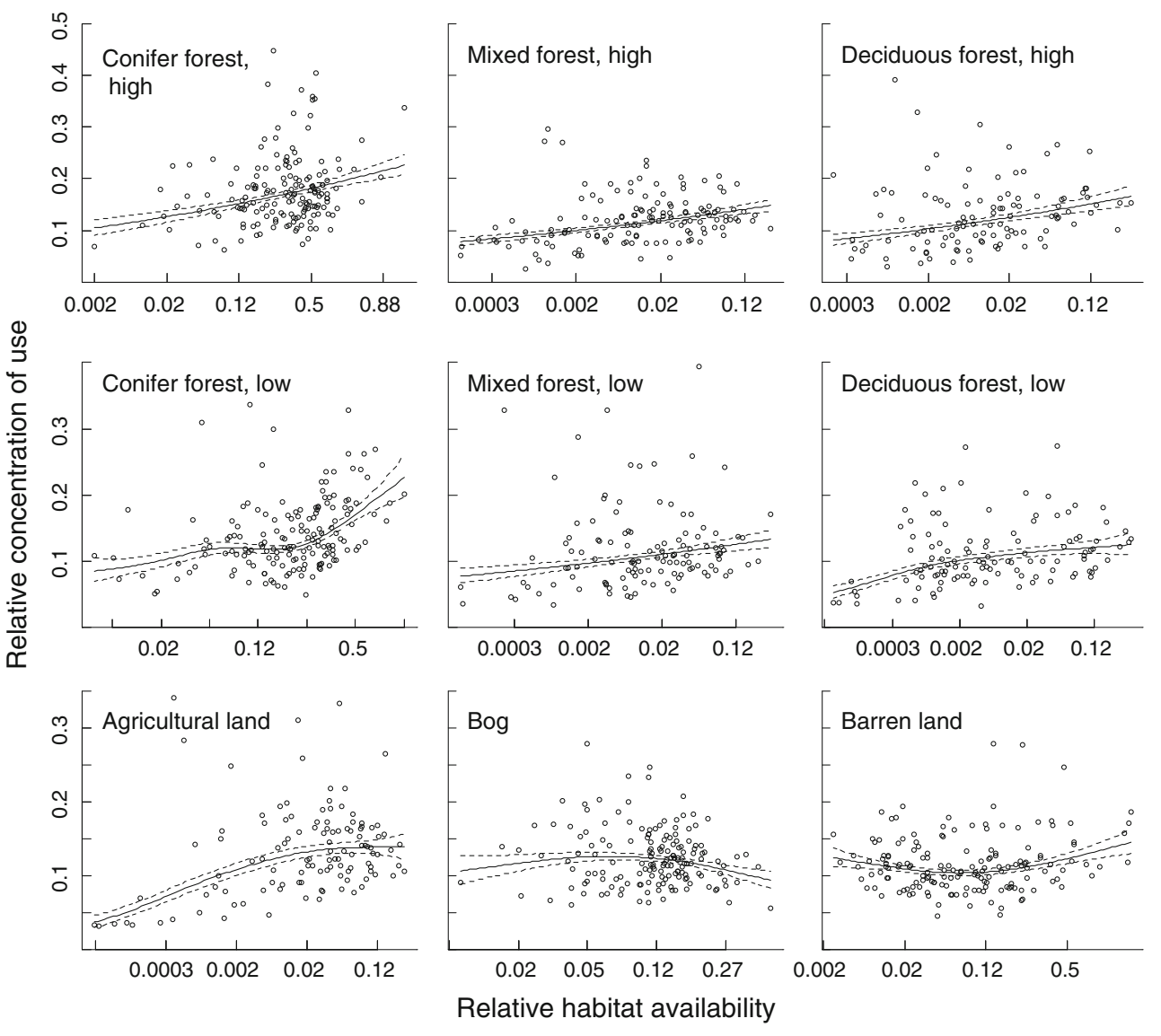

$P=0.019)$. For the remaining habitat types, we found no relationship between availability and home range size $(P>0.05)$, possibly due to low variation in availability for several habitat types.

Functional response in habitat selection

For habitat types providing food and cover, or food only, we found evidence for functional responses in habitat selection, where concentration of use increased relative to the proportional occurrence of the habitat (Fig. 6). The results from the GAMMs indicated a non-linear functional response for several habitat types (i.e. low-productivity deciduous forest: $e d f=2.3, P<0.001$; low-productivity coniferous forest: $e d f=3.6, P<0.001$; and agricultural land: $e d f=2.5, P<0.001$; Fig. 6), whereas for other the response was linear [edf $=1$, high-productivity deciduous forest: $\beta=0.54$ (proportion of the habitat type and concentration of use on logit scale), $P=0.003$, low- and highproductivity mixed forest: $\beta=0.13, P=0.020$ and $\beta=0.16, P<0.001$, respectively, and high-productivity coniferous forest: $\beta=0.13, P<0.001]$. We found no functional response for bog as there was no change in concentration of use with relative availability $(P=0.114)$. The relationship between relative concentration of use and relative availability of barren land was non-linear between home ranges $(e d f=2.3, P=0.023)$, but did not show any clear pattern of increase (Fig. 6).

\section{Effects of habitat composition on local density}

The population density index varied among municipalities $(n=27)$ within the study area (mean $=0.50, \mathrm{SD}=0.42$, range $=0.04-3.50)$. When examining the relationship between the index of population density and proportion of different habitat types, we found the density index to be lower in municipalities where the area defined by the land cover maps (see "Materials and methods") consisted of high proportion of barren land $(\beta=-0.18, \quad \mathrm{SE}=0.07$, $P=0.018$, density and proportion of the habitat type is on $\log$ and logit scale, respectively), mixed forest $(\beta=-0.42$, $\mathrm{SE}=0.07, \quad P=0.001 \quad$ and $\quad \beta=-0.75, \quad \mathrm{SE}=0.11$, $P<0.001$ for low- and high-productivity, respectively) and low-productivity deciduous forest $(\beta=-0.14, \mathrm{SE}=0.06$, $P=0.031)$. In contrast, the density index was higher in municipalities with high proportion of agricultural land $(\beta=0.54, \mathrm{SE}=0.05, P<0.001)$ and unrelated to the proportion of coniferous forest $(P=0.842$ and $P=0.366$ for low- and high-productivity, respectively), high-productivity deciduous forest $(P=0.208)$ and bog $(P=0.390)$. 


\section{Discussion}

Our results show that moose are selective in their choice of habitat types within summer home ranges, indicating that habitat types differ in their attractiveness to moose. In general, food appears to govern the choice of habitat type as moose selected high-productivity forests over low-productivity forests. Moose also selected cover, particularly females with young. In addition, moose increased their selection for habitat types associated with good or intermediate foraging conditions when the relative supply of these habitat types increased, indicating functional responses in habitat selection. We also observed variations in animal space use related to the supply of habitat types providing different resources.

Moose showed a general preference for abundant habitat types providing forage of intermediate quality, whereas the expected selection for habitat types providing abundant, high quality forage was not as evident (Fig. 3). For instance, females did not show as strong selection for deciduous forest and high-productivity mixed forest as expected, despite the high abundance of preferred forage in these habitat types (Fig. 2). Possibly, this was because low availability of deciduous and mixed forest stands (Fig. 4) made it less profitable for moose to search for and visit these habitat types in accordance with their feeding value. Additionally, moose did not avoid more abundant low-productivity habitat types as clearly as expected. This suggests that not only foraging conditions but also habitat availability is important for habitat selection by moose in summer. For habitat types offering beneficial resources for moose, we speculate whether availability is more important than quality. Indeed, it is suggested that varying supply of different habitat types between home ranges should affect habitat selection (Mysterud and Ims 1998). Thus, to correctly verify which habitat types are preferred to others, it is important to take into consideration the availability of the different habitat types. Moreover, habitat heterogeneity can influence habitat selection, but evidence for selection of heterogeneous environments is often found at larger spatial scales (Kie et al. 2002; Boyce et al. 2003). Although we did not study selection for heterogeneity, we found most moose home ranges to include a diversity of habitat types (Table 1).

Among the most abundant habitat types (Fig. 4), moose generally selected high-productivity coniferous forest over low-productivity coniferous forest, barren land and bog. This suggests that moose are likely to select abundant habitat types providing the best foraging conditions. Barren land and bog provide little food or cover, whereas lowproductivity coniferous forest evidently provide less preferred food plants than high-productivity coniferous forest (Fig. 2c, d, f, h). We also speculate that the density and cover of preferred food plants may be much higher in the utilised part of the high-productivity coniferous forest than indicated in Fig. 2. This forest type is heavily utilised by forestry because of faster growth (Larsson and Hylen 2007), and consists of a patchwork of even-aged forest stands of which a large proportion is regenerating forest. Transitory forest habitat types have long been recognized as important feeding habitats for moose because of their higher cover of attractive forbs, high density of deciduous trees, and because most plants are within reach of moose (Peek 1997; Bjørneraas et al. 2011).

When accounting for dissimilar habitat availabilities among moose, we found that the selection for habitat types providing food and/or cover tended to increase with relative availability between home ranges (i.e, not proportional use), and for several habitat types this response was nonlinear (Fig. 6). This indicates functional responses in habitat selection, and that the value of a habitat type providing beneficial resources is relative to its availability. However, contrary to our results, several recent studies have found selection for favoured habitat types to be higher when availability is low (Godvik et al. 2009; Herfindal et al. 2009; Wam and Hjeljord 2010). A possible explanation is that good availability of a habitat type reduces the cost for searching and visiting it, and thus increases selection for that habitat type. Also, other ungulate studies have found similar results where the relative probability of use of a resource increased with increasing availability (Boyce et al. 2003; Wam and Hjeljord 2010). This positive relationship between selectivity for a resource and its availability can be due to declining abundance of higher quality resources (Wam and Hjeljord 2010).

Interestingly, the relative use of more unproductive habitat types (bog and barren land) varied little with availability for moose in our study. We believe that these habitat types are qualitatively similar to moose from a feeding or cover point of view, but are merely unavoidable landscape elements connecting habitat types with food and cover. Although the increasing preference for both agricultural land and low-productivity deciduous forest tended to level off with increasing accessibility, a wider range of availabilities for agricultural land, mixed forest and deciduous forest should be present to reveal functional responses for these habitat types. We note that varying ranges of availability for the different habitat types included in this study makes it difficult to compare the functional responses among habitats.

Habitat selection may vary according to sex or reproductive status when there are demographical differences in cost or benefits associated with visiting a habitat (Main 2008). Females accompanied by young generally prefer areas with cover and avoid open areas which may be related to higher predation risk (White and Berger 2001; Dussault et al. 2005a; Main 2008). We found that females 
with young selected forest over all other habitat types (Fig. 3). In particular, their preference for low productive coniferous forest to open agricultural land indicates that reduced predation risk may be traded for lower quality forage. Accordingly, avoidance of open habitat types in order to protect young can to some extent affect habitat selection. However, due to the low density of large carnivores in the study area and in Norway in general (Wabakken et al. 2007; Wartiainen et al. 2009), we suggest that preference for cover is a response to human activity as moose in our study area are heavily harvested (Lykkja et al. 2009). Although females without young and males also selected forest, they did not avoid open areas to the same extent as reproducing females (Fig. 3). Additionally, we found males to show a higher selection for habitat types providing high quality forage than females (Fig. 3). The lack of clear differences in the availability of habitat types within home ranges among the demographic groups (Fig. 4) suggests that these observed patterns are more a result of different habitat preference than spatial segregation (e.g. Miquelle et al. 1992) in this moose population.

The availability of habitat types of dissimilar qualities also influenced moose home range sizes. Home range size was larger when the relative within home range abundance of habitat types with presumed lower feeding value was high (Fig. 5). Additionally, home range size decreased with increasing proportion of agricultural land and high-productivity coniferous forest. Such relationships can be expected from the habitat productivity-home range size hypothesis (Harestad and Bunnell 1979) and supports recent findings in studies of ungulates where home ranges were reported to be smaller when important resources were abundant (Hansen et al. 2009; Herfindal et al. 2009; van Beest 2011). The distribution of resources within the home ranges may also explain observed variation in ungulate home range size (Kie et al. 2002). In our study area, moose select habitat types providing cover and food (Bjørneraas et al. 2011), and the distribution of these resources can potentially influence home range size. If cover and food are spatially segregated, home range size may be larger than if they coincide. Indeed, it is suggested that cover may influence moose space use more than forage during summer, and as a result home range sizes may even increase despite increasing browse density (Dussault et al. 2005b; Van Beest et al. 2011). As high-productivity coniferous forest provides both cover and food, this may explain why we found home ranges with a high proportion of this habitat type to be smaller (Fig. 5).

At the landscape scale, we found that moose to some extent distribute themselves according to the distribution of habitat types of different qualities, supporting the ideal free distribution hypothesis (Fretwell and Lucas 1969). Accordingly, we found the local population density index to be lower in municipalities with high cover of habitat types providing relatively poor forage conditions (barren land, low-productivity mixed forest, but also low-productivity deciduous forest) and higher in municipalities with high availability of agricultural land. This is also in accordance with our findings of small home range sizes for individuals with high availability of agricultural land, indicating that this habitat type may support a large number of moose relative to its area. However, as both mixed and deciduous forest, as well as agricultural land, constitute minor parts of the available areas (Fig. 4), the relationship between moose density and these habitat types may partly be a consequence of other non-measured factors. We found no relationship between the density index and the most preferred habitat types, indicating that moose distribute themselves only partly according to habitat characteristics at a larger spatial scale. This was not entirely surprising since all moose populations in Norway are managed at density levels determined by a trade-off between costs (e.g. forest and agricultural damage, traffic accidents) and benefits (hunting opportunities) at the local level. Thus, even in municipalities with highly productive habitat types, moose density may be moderate because of other societal priorities.

Acknowledgments We are grateful to the County Governor office in Nord-Trøndelag, the Directorate for Nature Management, the Norwegian Research Council (Norklima, Miljø 2015), project 184903/S30, Predclim, the National Road Administration and the National Rail Administration for financial support, and appreciate the financial contributions from many municipalities and landowners in the study area. We thank P.H. Pedersen at the County Governor office in Nord-Trøndelag for initiating the study and providing the necessary organisational structure, and K. Hobbelstad, R. Astrup and R. Eriksen at the Norwegian Forest and Landscape Institute for access to data from the National Forest Inventory. We acknowledge all veterinarians, technicians and local field workers for their help in collaring the moose and collecting reproduction data. M. Heim did an excellent job in organising the data. We also thank M. Hewison, S. Saï, D.A. Kelt, E. Gurarie and one anonymous referee for comments on earlier versions, and L. Börger for methodological advisees.

Open Access This article is distributed under the terms of the Creative Commons Attribution Noncommercial License which permits any noncommercial use, distribution, and reproduction in any medium, provided the original author(s) and source are credited.

\section{References}

Aarts G, MacKenzie M, McConnell B, Fedak M, Matthiopoulos J (2008) Estimating space-use and habitat preference from wildlife telemetry data. Ecography 31:140-160. doi:10.1111/j.2007. 0906-7590.05236.x

Bates D, Maechler M (2008) lme4: linear mixed-effects models using S4 classes. R package version 0.999375-28

Bjørdal I, Bjørkelo K (2006) AR5 klassifikasjonssystem. Klassifikasjon av arealressurser. Håndbok fra Skog og landskap, Norwegian Forest and Landscape Institute, Ås, Norway 
Bjørneraas K, Van Moorter B, Rolandsen CM, Herfindal I (2010) Screening Global Positioning System location data for errors using animal movement characteristics. J Wildl Manag 74:1361-1366. doi:10.2193/2009-405

Bjørneraas K, Solberg EJ, Herfindal I, Van Moorter B, Rolandsen CM, Tremblay J-P, Skarpe C, Sæther B-E, Eriksen R, Astrup R (2011) Moose Alces alces habitat use at multiple temporal scales in a human-altered landscape. Wildl Biol 17:44-54. doi:10.2981/ 10-073

Börger L, Franconi N, De-Michele G, Gantz A, Meschi F, Manica A, Lovari S, Coulson T (2006) Effects of sampling regime on the mean and variance of home range size estimates. J Anim Ecol 75:1393-1405. doi:10.1111/j.1365-2656.2006.01164.x

Boyce MS, Mao JS, Merrill EH, Fortin D, Turner MG, Fryxell J, Turchin P (2003) Scale and heterogeneity in habitat selection by elk in Yellowstone National Park. Ecoscience 10:421-431

Brown JS (1988) Patch use as an indicator of habitat preference, predation risk, and competition. Behav Ecol Sociobiol 22:37-47

Calenge C (2006) The package "adehabitat" for the R software: a tool for the analysis of space and habitat use by animals. Ecol Model 197:516-519

Charnov EL (1976) Optimal foraging, marginal value theorem. Theor Popul Biol 9:129-136

Dussault C, Courtois R, Ouellet JP, Girard I (2005a) Space use of moose in relation to food availability. Can J Zool 83:1431-1437. doi:10.1139/z05-140

Dussault C, Ouellet J-P, Courtois R, Huot J, Breton L, Jolicoeur H (2005b) Linking moose habitat selection to limiting factors. Ecography 28:619-628. doi:10.1111/j.2005.0906-7590.04263.x

Fretwell DS, Lucas HL (1969) On territorial behavior and other factors influencing habitat distribution in birds I. Theoretical development. Acta Biotheor 19:16-32

Garel M, Solberg EJ, Sæther B-E, Grøtan V, Tufto J, Heim M (2009) Age, size, and spatiotemporal variation in ovulation patterns of a seasonal breeder, the Norwegian moose (Alces alces). Am Nat 173:89-104. doi:10.1086/593359

Godvik IMR, Loe LE, Vik JO, Veiberg V, Langvatn R, Mysterud A (2009) Temporal scales, trade-offs, and functional responses in red deer habitat selection. Ecology 90:699-710. doi:10.1890/ 08-0576.1

Hanley TA (1997) A nutritional view of understanding and complexity in the problem of diet selection by deer (Cervidae). Oikos 79:209-218. doi:10.1139/Z07-015

Hansen BB, Herfindal I, Aanes R, Sæther B-E, Henriksen S (2009) Functional response in habitat selection and the tradeoffs between foraging niche components in a large herbivore. Oikos 118:859-872. doi:10.1111/j.1600-0706.2009.17098.x

Harestad AS, Bunnell FL (1979) Home range and body-weight - Reevaluation. Ecology 6:389-402

Herfindal I, Tremblay J-P, Hansen BB, Solberg EJ, Heim M, Sæther BE (2009) Scale dependency and functional response in moose habitat selection. Ecography 32:849-859. doi:10.1111/j.16000587.2009.05783.x

Hjeljord O, Hovik N, Pedersen HB (1990) Choice of feeding sites by moose during summer, the influence of forest structure and plant phenology. Ecography 13:281-292. doi:10.1111/j.1600-0587. 1990.tb00620.x

Hobbs NT, Gross JE, Shipley LA, Spalinger DE, Wunder BA (2003) Herbivore functional response in heterogeneous environments: a contest among models. Ecology 84:666-681. doi:10.1890/00129658(2003)084[0666:HFRIHE]2.0.CO;2

Holling CS (1959) Some characteristics of simple types of predation and parasitism. Can Entomol 91:385-398

Horne JS, Garton EO, Krone SM, Lewis JS (2007) Analyzing animal movement using brownian bridges. Ecology 88:2354-2363. doi: 10.1890/06-0957.1
Huck M, Davison J, Roper TJ (2008) Comparison of two sampling protocols and four home-range estimators using radio-tracking data from urban badgers Meles meles. Wildl Biol 14:467-477. doi:10.2981/0909-6396-14.4.467

Johnson CJ (1980) The comparison of usage and availability measurements for evaluating resource preference. Ecology 61:65-71. doi:10.2307/1937156

Karlsen SR, Elvebakk A, Høgda KA, Johansen B (2006) Satellitebased mapping of the growing season and bioclimatic zones in Fennoscandia. Glob Ecol Biogeogr 15:416-430. doi:10.1111/ j.1466-822X.2006.00234.x

Kie JG, Bowyer RT, Nicholson MG, Boroski BB, Loft ER (2002) Landscape heterogeneity at differing scales: effects on spatial distribution of mule deer. Ecology 83:530-544. doi:10.1890/ 0012-9658(2002)083[0530:LHADSE]2.0.CO;2

Larsson JH, Hylen G (2007) Skogen i Norge. Statistikk over skogforhold og skogressurser i Norge registrert i perioden 2000-2004 [Statistics of forest conditions and forest resources in Norway]. Viten Skog Landskap 1:1-91

Lykkja O, Solberg EJ, Herfindal I, Wright J, Rolandsen CM, Hanssen MG (2009) The effects of human activity on summer habitat use by moose. Alces 45:109-124

Maier JAK, Ver-Hoef JM, McGuire AD, Bowyer RT, Saperstein L, Maier HA (2005) Distribution and density of moose in relation to landscape characteristics: effects of scale. Can J For Res 35:2233-2243. doi:10.1139/X05-123

Main MB (2008) Reconciling competing ecological explanations for sexual segregation in ungulates. Ecology 89:693-704. doi: 10.1890/07-0645.1

Marzluff JM, Millspaugh JJ, Hurvitz P, Handcock MS (2004) Relating resources to a probabilistic measure of space use: forest fragments and Steller's jays. Ecology 85:1411-1427. doi: 10.1890/03-0114

McNamara JM, Houston AI (1994) The effect of a change in foraging options on intake rate and predation rate. Am Nat 144:978-1000

Miquelle DG, Peek JM, Vanballenberghe V (1992) Sexual segregation in Alaskan moose. Wildl Monogr 122:1-57. doi:10.2307/ 3830827

Mysterud A, Ims RA (1998) Functional responses in habitat use: availability influences relative use in trade-off situations. Ecology 79:1435-1441. doi:10.1890/0012-9658(1998)079[1435: FRIHUA]2.0.CO;2

National Cervid Register (2011) www.hjortevilt.no (A national register for wild ungulate monitoring data)

Neatherlin EA, Marzluff JM (2004) Responses of American crow populations to campgrounds in remote native forest landscapes. J Wildl Manag 68:708-718. doi:10.2193/0022-541X(2004)068 [0708:ROACPT]2.0.CO;2

Nikula A, Heikkinen S, Helle E (2004) Habitat selection of adult moose Alces alces at two spatial scales in central Finland. Wildl Biol 10:121-135

Peek JM (1997) Habitat relationships. In: Schwartz CC, Franzmann AW (eds) Ecology and management of the North American moose. Smithsonian Institute Press, London, pp 351-375

Pinheiro JC, Bates DM (2000) Mixed-effects models in S and S-PLUS. Springer, New York

R Development Core Team. (2010) R: a language and environment for statistical computing, Vienna

Rettie WJ, Messier F (2000) Hierarchical habitat selection by woodland caribou: its relationship to limiting factors. Ecography 23:466-478. doi:10.1111/j.1600-0587.2000.tb00303.x

Rolandsen CMR, Solberg EJ, Bjørneraas K, Heim M, Van Moorter B, Herfindal I, Garel M, Pedersen PH, Sæther B-E, Lykkja ON, Os $\varnothing$ (2010) Elgunders $\varnothing$ kelsene i Nord-Trøndelag, Binal og Rissa 2005-2010 - Sluttrapport. NINA Rapport 588, Trondheim 
Rosenzweig ML (1981) A theory of habitat selection. Ecology 62:327-335. doi:10.2307/1936707

Rosenzweig ML (1991) Habitat selection and population interactions-the search for mechanism. Am Nat 137:S5-S28

Schoener TW (1971) Theory of feeding strategies. Annu Rev Ecol Syst 11:369-404. doi:10.1146/annurev.es.02.110171.002101

Solberg EJ, Sæther B-E, Strand O, Loison A (1999) Dynamics of a harvested moose population in a variable environment. J Anim Ecol 68:186-204. doi:10.1046/j.1365-2656.1999.00275.x

Spalinger DE, Hobbs NT (1992) Mechanisms of foraging in mammalian herbivores-new models of functional-response. Am Nat 140:325-348

Van Beest FM, Rivrud IM, Loe LF, Milner JM, Mysterud M (2011) What determines variation in home range size across spatiotemporal scales in a large browsing herbivore? J Anim Ecol 80(4):771-785. doi:10.1111/j.1365-2656.2011.01829.x_2011

Wabakken P, Aronson A, Strømseth TH, Sand H, Svensson L, Kojola I (2007) Ulv i Skandinavia: statusrapport for vinteren 2006-2007. Høgskolen i Hedmark Oppdragsrapport nr 6
Wam HK, Hjeljord O (2010) Moose summer and winter diets along a large scale gradient of forage availability in southern Norway. Eur J Wildl Res 56:745-755. doi:10.1007/s10344-010-0370-4

Wartiainen I, Tobiassen C, Brøseth H, Bjervamoen SG, Eiken HG (2009) Populasjonsovervåkning av brunbjørn 2005-2008: DNA analyse av prøver samlet i Norge i 2008. Bioforsk Rapport vol 4 no 58

White RG (1983) Foraging patterns and their multiplier effects on productivity of northern ungulates. Oikos 40:377-384. doi: $10.2307 / 3544310$

White KS, Berger J (2001) Antipredator strategies of Alaskan moose: are maternal trade-offs influenced by offspring activity? Can J Zool 79:2055-2062. doi:10.1139/cjz-79-11-2055

Wood S (2006) Generalized additive models: an introduction with R. Chapman \& Hall/CRC, Boca Raton 